\title{
O GOVERNO DA MOBILIDADE HAITIANA NO BRASIL"
}

\author{
Rosa Vieira
}

No começo de 2010, Sista Telemaque, uma haitiana de 18 anos, ingressou no Brasil pela fronteira de Corumbá, no Mato Grosso do Sul. Ela foi detida, junto com outras pessoas haitianas, porque não possuía visto para transitar no país. Nesse período, pouco se falava a respeito do ingresso no Brasil de pessoas vindas do Haiti. Dois anos depois, em 2013, ao buscar informações sobre essas detenções, conversei com o assessor de imprensa da Polícia Federal de Campo Grande (MS). Ele me respondeu: “Não é a gente que você tem que procurar, não se tornou um caso de polícia [os haitianos], se tornou um caso de governo, sabe, quando entraram a mídia, as ONGs, aí a gente passou para outro órgão, virou um caso político e não da polícia". Ainda que a atuação da polícia seja uma ação de governo - forças policiais são um dispositivo de governo - a distinção feita pelo assessor entre "caso de polícia" e "caso político" é interessante por indicar a percepção de uma mudança. Na conversa, o que ele estava me dizendo? Ao longo deste artigo ofereço algumas chaves de análise para termos uma compreensão nuançada do sentido da pergunta.

O assessor buscou separar um caso de polícia de um caso político estabelecendo um marco de ruptura entre o momento da detenção de Sista e um momento posterior que teria outra dimensão. Embora, como já analisado (Vieira 2014, 2016), neste contexto de detenções houvesse o começo do desenho de uma população e ações para enquadrá-la, um caso de governo se construiu apenas nos primeiros meses de 2011, colocando o tema da mobilidade haitiana na agenda pública, envolvendo agências variadas e propiciando que os ingressos no Brasil de pessoas vindas do Haiti se transformassem em um "caso político", como disse o assessor.

A população do Haiti corresponde a cerca de 10,5 milhões de pessoas (The World Factbook, CIA 2016) e é estimado que milhões residam no exterior. Partidas dos haitianos em direção a outros países, como República Dominicana, Cuba, Bahamas, Estados Unidos, França, Canadá, fazem parte da história do Haiti. Algumas pesquisas enfatizaram especificamente as múltiplas relações e os laços que haitianos situados em outros países mantêm 
com lugares (casas, terras e cidades de origem) e com os seus próximos (Glick-Schiller \& Fuoron 2001; Richman 2008; Handerson 2015). ${ }^{1}$ Há um espaço sociogeográfico haitiano que incorpora pessoas e objetos espalhados por diversas localidades.

Nos últimos seis anos, o Brasil passou a fazer parte deste espaço. ${ }^{2}$ Isso se deu numa conjuntura política internacional em que forças brasileiras comandavam desde 2004 a Mission des Nations Unies pour la Stabilisation du Haiti (Minustah). O envolvimento da Organização das Nações Unidas (ONU) no país caribenho nos revela questões de governo e humanitarismo, bem como lança luz quanto à gestão internacional de populações que devem ser controladas, "ajudadas", e que são objetos de projetos de agências internacionais e organizações não governamentais. Em 2010, o Haiti foi devastado por um terremoto que matou mais de 200 mil pessoas e atingiu a capital, Porto Príncipe. Boa parte das dificuldades atuais do país já estava presente antes do sismo, mas o evento destruiu iniciativas e projetos bem-sucedidos (cf. Neiburg 2010).

Naquele momento, a economia brasileira apresentava altos índices de crescimento e uma baixa taxa de desemprego. A conjuntura internacional e os contextos do Brasil e do Haiti poderiam nos levar a uma explicação causal e linear: as pessoas partiram do Haiti devido ao terremoto e vieram ao Brasil por causa da Minustah e do crescimento econômico. Mas é importante, primeiro, considerar que a população haitiana é, como já assinalado, histórica e estruturalmente diaspórica, o Brasil não sendo o primeiro e nem único destino das partidas. Também não podemos perder de vista que nacionais do Haiti já habitavam e circulavam pelos países da América do Sul antes do terremoto, como no Equador, Suriname e Guiana Francesa. Há indicativos de que pessoas haitianas ingressadas pela fronteira norte amazônica, principalmente em 2010 e 2011, pretendiam alcançar a Guiana Francesa (Handerson 2015) e o Brasil era apenas um território de passagem.

Contextos e conjunturas nos ajudam a montar um cenário onde uma série de ações e narrativas se delinearam, fazendo com que o ingresso no Brasil de pessoas vindas do país caribenho se tornasse uma temática na mídia, em reuniões governamentais e na academia. Ao analisar essas narrativas, é possível notar como saberes e poderes se inter-relacionam contribuindo para criar modelos padronizados sobre a mobilidade haitiana ao mesmo tempo em que produzem uma categoria de gestão: os "haitianos". O esforço neste artigo é observar de que maneira esta categoria passa a ser mobilizada no Brasil acompanhada de palavras como "fluxo", "problema", "questão", algo que se delineou através da comunicação e da articulação entre atores e agências, alguns motivados por razões humanitárias, disponibilizando "ajuda" aos migrantes, outros procurando evitar o aumento dos ingressos no Brasil. 
Os materiais utilizados foram reunidos durante uma pesquisa de mestrado desenvolvida entre 2013 e 2014 (Vieira 2014), que compreendeu uma estadia em Brasília em 2013 trabalhando como voluntária no Instituto de Migrações e Direitos Humanos (IMDH) e na secretaria do Conselho Nacional de Imigração (CNIg) no Ministério do Trabalho e Emprego. Nesse tempo de tarefas burocráticas, entrevistei e conversei com representantes de outras instituições e agências e pude reunir um conjunto de documentos que faziam referência à migração de haitianos. Tal conjunto não fazia propriamente parte de um arquivo oficial; ele compreendia papéis guardados em pastas e arquivos de computadores de gestores ou funcionários (de ministérios, órgãos, instituições, agências variadas). Eram documentos de espécies de "arquivos pessoais", nos quais constavam, por exemplo, desde um ofício carimbado de uma secretaria do governo do estado do Acre e relatórios de missões do governo federal até um e-mail enviado por um civil e que havia sido impresso e grampeado junto a uma notícia de jornal.

Arquivos podem ser considerados como documentos conectados - associados ou em rede, de acordo com Hull (2012) - que precisam guardar algo. Seja guardar os segredos oficiais, como já lembrava Weber (1974) de que o segredo é próprio da burocracia, seja como registro das ações da burocracia, de agências específicas e das pessoas que trabalham nessas agências. Os dois aspectos, principalmente o segundo, estavam em jogo nesses arquivos pessoais aos quais tive acesso, posto que em meio às disputas entre ministérios, os ocupantes dos altos cargos, os diferentes níveis da hierarquia, os atores faziam seus arquivos para registrar os seus próprios trabalhos, as reuniões das quais participaram ou como eram procurados através de ofícios por outros atores. É preciso lembrar que, ao me deixarem ter acesso a seus arquivos pessoais, eles queriam me mostrar como estavam participando da "questão dos haitianos" e como tinham se envolvido com este caso desde o início. Mas além disso - e este ponto é central para a presente discussão - tais "arquivos pessoais" me permitiram reconstituir, conectando e contrastando documentos, relatos dos atores entrevistados, notícias circuladas na mídia e observações feitas pelas experiências de campo em Brasília, como se inscreveram os "haitianos" enquanto uma categoria de gestão e um objeto de governo. ${ }^{3}$

A análise se insere em duas linhas de discussão, a primeira de alguma forma inspirada na segunda. A primeira tem a ver com o uso do conceito de mobilidade para analisar como a noção de "fluxo migratório" é construída e circulada antes mesmo da certeza de que pessoas do Haiti vinham ao Brasil para aqui residir. Falar em mobilidade permite considerar as várias dinâmicas que envolvem a circulação de pessoas e objetos, como já mostradas 
por alguns autores (Rabossi 2004; Guedes 2013; Comerford 2015; Handerson 2015), sem limitar esse processo à entrada e à integração do migrante em um Estado-nação ou em uma sociedade. A "imigração" é entendida neste texto enquanto produto de um esforço de classificar, enquadrar e ordenar a circulação das pessoas.

A segunda discussão é sobre o "governo das pessoas" na linha das formulações de Michel Foucault a respeito da "governamentalidade" (2008). Segundo o autor, "governo" tem relação com o conjunto de técnicas e procedimentos para a conduta dos viventes, por isso ele se refere ao governo das almas, ao governo das crianças, ao governo de uma casa, ao governo de uma população. Esta última dimensão (governo de uma população) foi explorada por ele através do conceito de governamentalidade, que pode ser definido como um conjunto constituído por agências, agentes, instituições, análises, reflexões, cálculos e táticas que permitem exercer uma forma de gestão voltada não propriamente para a manutenção da soberania sobre um território, mas para o governo de uma população por meio de mecanismos de segurança fundados no conhecimento. Importante para a sua perspectiva de segurança é a ideia de meio: a gestão de um meio em função de uma série de eventos, inscrevendo um campo de intervenção (2008:144). ${ }^{4}$ Didier Fassin recupera a discussão de Foucault para argumentar que as migrações são o principal objeto da governamentalidade contemporânea, tanto porque elas estão relacionadas à construção e à operação de fronteiras quanto porque se inserem nos três "pilares da governamentalidade": a economia, a polícia e o humanitarismo (Fassin 2011:221).

O processo de construção de um "Caso" e de uma categoria de governo está vinculado à construção de um "problema" de governo. ${ }^{5}$ Analisar a construção de um problema - "problematisation", como sugere Foucault (1994:670) - não é explorar as representações de um objeto preexistente e nem a criação pelo discurso de algo que não existe, mas sim o conjunto de práticas discursivas e não discursivas que fez em determinado momento que a mobilidade haitiana se tornasse um problema, dando lugar a ações, análises, discussões e se constituindo em objeto de gestão e do saber. ${ }^{6}$ É relevante notar que não convém pensarmos se o problema dos "haitianos" no Brasil de fato existiu ou se foi inventado, se foi uma ficção criada por autoridades do Acre, por exemplo, ou se ocorreu "realmente". A construção de um problema começa por nomeá-lo. E será esse processo de dar nome a uma nova dinâmica e as ações desenvolvidas para governá-la que são observados no artigo. 
A primeira parte do artigo é voltada para a análise de comunicados de atores e agências do Amazonas e do Acre. A maioria dos ingressos de pessoas haitianas nos anos de 2010 e 2011 foi terrestre, através de cidades como Tabatinga (AM) e Brasileia e recorrendo à solicitação de refúgio. A Lei $n^{\circ}$ 9474/1997 autoriza todo estrangeiro, uma vez no território brasileiro, a solicitar refúgio a uma autoridade migratória. Assim, nacionais do Haiti solicitavam refúgio no Departamento da Polícia Federal e adquiriam um protocolo com o qual tinham o direito de transitar legalmente no Brasil. ${ }^{7}$ Nessas cidades foram feitas as primeiras ações humanitárias por padres, freiras e autoridades locais, e dos quais vieram também pedidos ao governo federal para intervir. Os levantamentos de riscos associados à população haitiana e as ações para lidar com esses riscos são abordados na segunda parte do texto. Por fim, é analisada uma missão diplomática realizada pelo governo federal focando nos argumentos utilizados para justificar intervenções diretamente no trajeto de pessoas haitianas, como o combate ao "tráfico de pessoas" e ao "tráfico de migrantes".

\section{O desenho de um desbordo}

No final de 2010 e início de 2011, alguns atores do Amazonas e do Acre buscaram chamar a atenção do governo federal para que medidas fossem tomadas em relação aos migrantes haitianos. Em tais registros é possível notar a percepção do caráter não mais eventual dos ingressos e a movimentação da ideia de uma "situação" a ser resolvida, mas é perceptível como o processo se configura de forma diferente nas duas localidades apontadas.

A cidade de Tabatinga, no Amazonas, recebe um ou outro nacional do Haiti desde pelo menos o início de 2010. Ela fazia parte dos trajetos de pessoas haitianas que se dirigiam à Guiana Francesa e ao Suriname (Handerson 2015) através do estado do Amapá, atravessando o rio Oiapoque. Durante o trajeto, eles eram atendidos por uma integrante da Rede Solidária para Migrantes e Refugiados, a Pastoral da Mobilidade Humana, coordenada pela Irmã Patrícia. ${ }^{8}$ Em informe elaborado no dia 8 de janeiro de 2012, esta Irmã conta brevemente como foram as primeiras relações construídas para providenciar ajuda para os ingressados em 2010 e menciona que, devido ao "aumento do fluxo de entrada dos haitianos", em setembro de 2010 ficou complicado continuar com a ajuda para hospedagem e alimentação (Informe Pastoral da Mobilidade Humana 2012). Tal comunicado nos indica o início do desenho do que chamo aqui de um desbordo. 
Juan Carlos Velasco (2014) ressalta que os movimentos migratórios geralmente são tratados e pensados através do uso de metáforas, e as mais mobilizadas são principalmente as hídricas: "fluxo", "ondas", "correntes". Diferente de "fluxo", utilizado no comunicado da Irmã, desbordo não foi uma categoria nativa empregada para se referir ao ingresso de pessoas haitianas. Embora o termo não deixe de ser uma metáfora hídrica (ele se refere ao rio que saiu do seu leito, seja por uma causa natural, seja por uma intervenção no seu curso), o seu uso busca fazer referência à percepção dos atores de que, em certo momento, "o rio transbordou". Desbordo procura traduzir, assim, a percepção de um antes e depois.

Tive acesso a um e-mail que havia sido enviado à ex-presidente Dilma Rousseff (2011) e encaminhado posteriormente às agências federais que lidam com migrações e refúgio no Brasil. ${ }^{9}$ Escrito por uma moradora de Manaus, o texto apresenta uma "situação [a] qual merece uma especial atenção por se tratar de gente que está sofrendo" e comunica a presença de cerca de 100 pessoas haitianas nesta cidade. Ela demanda um olhar da presidente: "Desculpe importuná-la mais [sic] precisamos de uma solução imediata, pois muitos estão sendo os gastos com essas pessoas tanto para a alimentação, moradia, remédio etc.".

Outro informe elaborado pela Irmã Rosa e o Padre Gelmino Costa, enviado de Manaus no dia 07 de fevereiro 2011, diz: "Dirigimo-nos aos senhores em comum acordo e apoiados também pela Rede Solidária para Migrantes e Refugiados, pois sentimos a necessidade de apresentar-lhes um pouco a situação dos haitianos que se encontram em nossa região" (Informe Pastoral do Migrante 2011a). É retomado o mesmo ponto também colocado no e-mail: é necessária uma solução. Eles se referem, todavia, a uma "solução" do status migratório dos solicitantes, pedindo "uma definição jurídica".

Este mesmo Padre Gelmino Costa contou brevemente em outro comunicado da Pastoral do Migrante, no dia 16 de março de 2011, sobre a mobilidade entre Tabatinga e Manaus (Informe Pastoral do Migrante 2011b). Normalmente, pessoas haitianas chegavam cansadas a Tabatinga, eram atendidas pela Pastoral da Mobilidade Humana e aguardavam até conseguirem um protocolo de refúgio. Em Manaus, diversas igrejas os acolheram, disponibilizando espaços para dormir e, em algumas ocasiões, para cozinhar. Buscando documentar tal assistência prestada, por exemplo, a Irmã Rosa da Pastoral do Migrante de Manaus havia escrito em 4 de março de 2011: "O presente relatório quer apenas ser um instrumento de memória histórica referente à assistência social prestada aos imigrantes haitianos chegados em Manaus a partir dos meses de janeiro de 2010 até início de março de 2011" (Relatório Pastoral do Migrante 2011). E apresenta uma lista de entidades envolvidas 
no processo de acolhida, o que sugere as redes de relações em formação para conseguir providenciar ajuda às pessoas haitianas que ali chegavam com dificuldades para se alimentar e se hospedar. Aos poucos elas iam encontrando um emprego, um bico aqui ou ali, partiam para outros locais, mas outros chegavam e precisavam contar com os esforços das paróquias.

Nos relatos citados percebemos a mobilização da categoria "haitianos". Mas ela tem um uso distinto de acordo com o discurso. Enquanto este relatório da Irmã Rosa procura ser um registro das ações de entidades religiosas, um instrumento de memória, nos outros comunicados de Tabatinga e de Manaus, o termo "haitianos" remete a pessoas que precisam de "ajuda" para continuar seus rumos. A categoria "ajuda" é chave no léxico do humanitarismo, do governo humanitário e de toda a dinâmica de atuação das pastorais e das congregações no Brasil. Os relatos também operam a partir de duas dimensões de uma ideia de "situação", tanto uma situação social - pessoas expostas à vulnerabilidade, gastos para ajudá-las com alimentação e hospedagem - quanto uma situação jurídica. Ainda presente nesses documentos está uma ideia de passagem: quando podiam, tais estrangeiros partiam (seja da casa paroquial onde estavam hospedados, seja da cidade). Mas, em termos gerais, o que a ideia de "situação dos haitianos" levanta? Ela indica algo mais cotidiano que passageiro. E, talvez mais do que isso, mostra a construção de uma população, ações com vista a atendê-la e agentes expressando as dificuldades de continuar lidando com a "ajuda".

Um desbordo também se nota em documentos do Acre, que foi outro estado, através da cidade Brasileia, por onde passaram muitas pessoas provenientes do Haiti nos últimos anos. Ações e reações foram movimentadas neste município, dinamizando agentes e relações políticas (entre eles, a prefeita de Brasileia, o governador, vereadores, deputados, senadores, procuradores) que, diferente dos comunicados do Amazonas, conseguiram um olhar mais atento da mídia e do governo federal.

Antes de alguns dos comunicados mencionados acima, agentes do governo federal já vinham tomando conhecimento do ingresso de pessoas haitianas, como pode ser percebido no relatório "Informação ao Senhor Ministro de Estado: fluxo migratório haitiano em direção ao Brasil", elaborado por uma funcionária do governo federal através de informações colhidas junto ao secretário de Ação Social do estado do Acre. Ao que tudo indica, ele foi produzido em janeiro de 2011 e foi utilizado por um ministro (não foi possível identificar qual) em seu despacho com a presidente. ${ }^{10}$ Até dezembro de 2010, como está salientado nesse documento, cerca de 630 processos de solicitação de refúgio foram registrados. O relatório aponta que inicialmente a quantidade de pessoas vindas do Haiti era reduzida 
de modo que o assunto não fora, como consta escrito, "elevado às altas instâncias governamentais". Mas depois menciona que o "súbito afluxo de dezenas de haitianos [à] cidade de Brasileia, em janeiro de 2011, mostrou-se preocupante e chegou ao conhecimento do governador do Acre, do ministro das Relações Exteriores e do secretário-executivo do Ministério da Justiça".

Como vemos, o "súbito afluxo" levou a temática a subir de patamar e a alcançar, possivelmente, uma reunião com a ex-presidente Dilma Rousseff ainda em janeiro de 2011. Mas isso se deveu principalmente aos contatos do governador do Acre. Já com um bom trânsito entre agentes do governo federal, o governador do estado do Acre, Sebastião Vianna (PT), irmão do senador Jorge Vianna (PT/AC), ativou suas relações, acionou a mídia e buscou chamar a atenção do governo federal.

No dia 21 de janeiro de 2011, uma notícia da Folha de São Paulo, jornal de grande circulação nacional, publicada com o título "Acre é rota de entrada de haitianos no país", menciona os esforços do governo do estado do Acre e da Igreja Católica para providenciar abrigo e alimentos para tais pessoas. ${ }^{11}$ Além do bom trânsito do governador Sebastião Vianna (PT/AC) por Brasília, a mídia contribuiu para dar visibilidade à "situação" anunciada, como também para produzi-la e reproduzi-la. Ambos chamaram a atenção de agências do governo federal em janeiro de 2011, sugerindo os seus êxitos em conseguir transformar os ingressos de pessoas vindas do Haiti em um assunto de agenda pública. Tanto é que no relatório utilizado no despacho com a ex-presidente, citado anteriormente, observamos referências apenas ao estado do Acre e nenhuma menção é feita a Tabatinga ou a Manaus, mesmo os números sendo mais elevados no estado do Amazonas.

\section{Riscos e controle}

Autoridades do governo do Acre, padres e freiras de entidades que lidam com migrantes e refugiados no Brasil buscaram chamar a atenção do governo federal para uma "situação" que precisava de uma solução no início de 2011. Também se assistiu neste momento ao levantamento de riscos que a presença haitiana no Brasil, na visão de alguns atores e agências, poderia representar.

O relatório "Migrações de haitianos para o Brasil", elaborado por uma agência de inteligência em outubro de 2010, oferece um breve panorama das informações circuladas nessa época: "Houve detecção de fluxo migratório irregular para o Brasil através dos estados do Amazonas e Mato Grosso do Sul. A maioria dos haitianos passa por República Dominicana, Panamá e 
Peru antes de ingressar no Brasil". Este trecho não se refere a um grupo ou outro de "haitianos", mas aos "haitianos" enquanto um fluxo migratório. Outro componente também foi central no desenvolvimento do relatório:

Existe o risco de que criminosos haitianos fugitivos possam entrar em território brasileiro por meio de rotas de migração, como a detectada em Tabatinga. A triagem realizada pelos postos de fronteira do DPF não inclui a checagem de antecedentes criminais dos haitianos que solicitam refúgio. Cerca de 4,5 mil presos fugiram da penitenciária de Porto Príncipe, no Haiti, após o terremoto de 12 de janeiro de 2010 (Anexo), sendo que a maioria deles não foi recapturada.

Durante o sismo de magnitude 7 que afetou mais de 3 milhões de pessoas e teve consequências sem precedentes para o país, a maior prisão de Porto Príncipe desabou com o tremor e os jornais passaram a anunciar a possível fuga dos prisioneiros. Os números variaram, alguns falavam em 6 mil presos soltos, outros apontavam para a fuga de pequenos contingentes. ${ }^{12}$

De acordo com o Estatuto para Refugiados brasileiro, Lei no 9474/97, todo estrangeiro tem o direito de solicitar refúgio, desde que ele não apresente um risco para o país. Faz parte dos procedimentos burocráticos verificar junto a sistemas de dados de indivíduos procurados o nome do solicitante. Se antes as autoridades não tinham receios com fugitivos do Haiti, quando a presença de pessoas vindas de lá passou a ser mais frequente - ainda que no Brasil apenas algumas centenas tivessem sido registradas - tal preocupação surgiu e foi objeto do relatório. ${ }^{13}$

Além do medo da chegada de prisioneiros, foi levantada a possibilidade de pessoas haitianas serem um risco para a saúde da população brasileira. Quando nos deparamos com o título da notícia do jornal A Crítica, do Amazonas, publicada no dia 08 de fevereiro de 2011, "FVS chega a Tabatinga para enfrentar cólera", a primeira interpretação do leitor é crer que o cólera já tinha se alastrado pela cidade. ${ }^{14}$ Todavia, o que se tentava era uma ação de prevenção, com o envio de uma comitiva da Fundação de Vigilância da Saúde (FVS/AM). É interessante pensar também por quais motivos o então senador João Paulo (PT/AM) encaminhou um ofício no dia 16 de fevereiro de 2011 ao Ministério da Justiça anexando a notícia supracitada. Se o intuito era chamar a atenção do governo federal para a "situação desesperadora" em Tabatinga, como ele se referiu no ofício, nada mais alarmante do que anunciar a possibilidade de uma epidemia de cólera. Este risco não foi, entretanto, apenas uma preocupação do senador e da FVS/AM.

No final de janeiro de 2011, o governo do Acre já havia solicitado ao Ministério da Saúde apoio nas ações da Secretaria Estadual de Saúde (SES) para investigar os "Migrantes haitianos no Acre - risco de reintrodução da 
cólera no Brasil", como o título do relatório situacional da missão, datado de 7 de fevereiro de 2011, envolvendo estas duas agências sugere. Tal documento tinha por objetivo descrever os riscos da disseminação do cólera no país, relatar as principais ações desencadeadas na área de saúde em relação às pessoas vindas do Haiti presentes no município de Brasileia (AC) e sugerir propostas de médio e longo prazos. Os novos habitantes - ainda que temporários - e apontamentos sobre as condições em que viviam hospedados em um ginásio da Prefeitura em Brasileia são apresentados com detalhes para fundamentar o levantamento do risco por agentes da saúde do Ministério e do governo do Acre. A inexistência do cólera entre nacionais do Haiti examinados foi apenas apresentada em breves passagens do relatório (a pesquisa foi realizada em 92 amostras de fezes e todas deram negativas).

O mesmo resultado encontraram as vigilâncias sanitárias de outras cidades. O "Relatório da situação epidemiológica das doenças diarreicas agudas (DDA) do município de Oiapoque - AP e controle de entrada de haitianos no município", por exemplo, foi circulado entre agências do governo federal em fevereiro de $2011 .{ }^{15}$ Neste documento são apresentadas informações sobre as condições sanitárias do município, que deixam "a população vulnerável para o surgimento de diversas doenças que podem ser prevenidas". A necessidade de prevenção, no entanto, ressurge quando indivíduos provenientes do Haiti circulam pela região. Mas, ao contrário do que se imaginava, também não foram identificados casos de cólera.

As ações e as precauções dos agentes de saúde mencionadas podem ter sido motivadas por alguns aspectos, como a rapidez da transmissão da doença, as experiências anteriores com o cólera no norte e nordeste brasileiros, a epidemia ocorrida no Haiti em 2010 que teve milhares de casos. ${ }^{16}$ Em alguma medida, a possibilidade de haver um caso de cólera no Brasil pode trazer receios, mas a preocupação sanitária também foi acompanhada de certo alarmismo e usada igualmente como uma maneira de controlar os ingressos. Quando olhamos a sucessão de relatórios e eventos de perto, é possível notar em que medida uma preocupação médica pode se configurar como um instrumento para classificar, criar padrões e desvios. Isto é possível perceber num outro relatório reunido durante o campo em Brasília, no qual são pontuados os assuntos discutidos em uma reunião do gabinete de gestão de crise do Ministério da Saúde ocorrida no dia 14 de fevereiro de 2011. Além de apontar as possibilidades do cólera em Tabatinga (AM), este documento tem um tópico, "Cólera em Ipojuca [Pernambuco]", em que é relatada a identificação de uma pessoa contaminada nesta cidade no nordeste do Brasil. Só que os encaminhamentos decididos consistem, como consta em tal documento, em enviar uma equipe para verificar "a presença 
de haitianos na região". A relação entre "o haitiano" e o cólera em tal caso aparece invertida. Se alguns documentos mencionados indicam ações para investigar a possível consequência, nas suas visões, dos ingressos de pessoas vindas do Haiti - a disseminação do cólera - nesse relatório identificaram a consequência (um caso de cólera) e queriam encontrar a causa ("a presença de haitianos").

Não é a primeira vez que a nacionalidade haitiana é associada à disseminação de doenças e epidemias. Como já discutiu Paul Farmer (1992), na década de 80, período de desconhecimento e incertezas sobre a difusão do vírus HIV e a AIDS, os migrantes haitianos foram classificados pelos Centers for Disease Control (CDC) americano como um dos quatro grupos de risco ("hatians", "homossexuels"; "hémophiles"; "héroinomanes"), além de outras discriminações que argumentavam, por exemplo, a origem haitiana da AIDS. O limitado embasamento científico de tais teses indica o racismo que motivou a vinculação desta nacionalidade à doença. Tanto neste caso da AIDS quanto na possibilidade do cólera no Brasil, estão em jogo representações coletivas sobre tais epidemias, doenças associadas por vezes à "pobreza" e ao "baixo desenvolvimento".

O uso de práticas médicas preventivas em relação a migrantes haitianos são formas de marcar distinções, de "fazer civilização", como diria Sidney Chalhoub (1993) quando analisa o pensamento médico e a ideologia racial durante os surtos de febre amarela no Brasil do final do XIX. O risco levantado de disseminação do cólera e, consequentemente, os exames empreendidos configuraram esforços de produzir e reproduzir diferenciações e hierarquias (ordem e desordem; limpeza e insalubridade; progresso e atraso) entre nações. Ele também nos indica as associações entre mobilidade e risco epidemiológico, muito presentes no século XIX, quando a preocupação de médicos e autoridades era controlar as epidemias, supervisionando os navios estrangeiros (Rebelo; Maio \& Hochman 2011). Um tipo semelhante de associação se assistiu no Brasil com a presença de pessoas haitianas, e foram elaboradas ações de prevenção de um possível "problema" que, nas suas visões, poderia se apresentar: a introdução do vibrião colérico a partir do ingresso de nacionais do Haiti. Foram respostas governamentais à mobilidade que corresponderam a ações de controle diretamente sobre os corpos de uma população específica. 


\section{Reuniões diplomáticas para uma gestão negociada}

Foram realizadas não apenas missões de saúde, mas também missões diplomáticas para lidar com o ingresso de haitianos. No dia 16 de março de 2011, a Folha de São Paulo publicou uma notícia apontando as medidas desenvolvidas pelo governo federal. Uma delas correspondia à suspensão pelo Ministério da Justiça (MJ) da possibilidade de solicitar refúgio em departamentos da Polícia Federal com o argumento da identificação de "uma rota de tráfico humano na fronteira do Brasil".${ }^{17}$ A outra menciona a missão de representantes de agências brasileiras em relação a autoridades peruanas e equatorianas. Interligadas, ambas se inserem na diretriz de encontrar meios para impedir a intensificação do fluxo, discutida por vários representantes de ministérios em reunião do dia 17 de janeiro de $2011 .^{18}$

A primeira missão diplomática foi composta por uma delegação de agentes do Ministério de Relações Exteriores, Ministério da Justiça, Departamento da Polícia Federal e da ABIN. Partiu no dia 28 de fevereiro de 2011 e teve duas paradas, Quito e Lima. Visava inaugurar um mecanismo de consulta de informações entre os países, compartilhar dados sobre a mobilidade haitiana, criar possibilidades de cooperação na área policial e de inteligência, como também verificar se alguma exigência de visto poderia ser estabelecida pelas agências equatorianas e peruanas para os indivíduos nascidos no Haiti (Relatório: "Equador e Peru. Assuntos consulares e migratórios. Imigrantes haitianos". Missão brasileira 2011).

Tanto Equador como Peru não exigiam visto de ingresso para pessoas haitianas. A missão propôs às delegações de ambos os países que alterassem as suas legislações para estrangeiros e determinassem algum tipo de visto para nacionais do Haiti. Mas antes de os haitianos se tornarem uma preocupação para o governo brasileiro, o Equador e o Peru já constituíam locais de trânsito e residência de pessoas vindas do Haiti. Dados apresentados no relatório dessa missão diplomática apontam que no Peru, em 2008, foram registradas 274 entradas e 278 saídas de nacionais do Haiti; em 2009, esses números subiram para 671/575; em 2010, foi para a casa dos mil, 1,777/1,893; e em janeiro e fevereiro de 2011, os números foram 659/326.

Em fevereiro de 2010, o presidente equatoriano Rafael Correa promulgou um decreto $\left(\mathrm{n}^{\circ} 248\right)$ por meio do qual viabilizou a regularização de estrangeiros de origem haitiana ingressados no país até 31 de janeiro de 2010 (beneficiando cerca de 400 a 500 pessoas), como uma forma de se solidarizar com a crise humanitária haitiana pós-terremoto. ${ }^{19} \mathrm{E}$ entre o início de novembro de 2010 e o final de janeiro de 2011 haviam sido registrados no Equador os ingressos de 734 pessoas vindas do Haiti. A proposta de 
exigência de visto buscava diminuir e controlar esses trânsitos. Entretanto, as respostas das delegações foram distintas. Como escrito neste mesmo relatório, o Equador mostrou "firme recusa ao pedido brasileiro de imposição de visto". Do lado do Peru, contudo, essa proposta foi bem recebida pelas autoridades, mas o estabelecimento do requerimento de visto para nacionais do Haiti só ocorreu no ano seguinte, no dia 10 de janeiro de 2012, pelo Decreto supremo número 001-2012-RE.

As negociações da missão não se limitaram ao pedido de visto. Como sugere uma das propostas da agenda da missão, escrita na folha de rosto do "Relatório prévio: Missão ao Equador e Peru - Imigração Haitiana, 2010", 20 a viagem também pretendeu fazer um "exame das possibilidades de cooperação bilateral (ou tripartite) na área policial e de inteligência, com vistas ao desbaratamento de redes de tráfico de pessoas que porventura atuem na rota em direção ao Brasil". Como vemos nesta citação, desbaratar a "rede de tráfico de pessoas" era um objetivo das autoridades brasileiras, de modo a construir uma rede de gestão policial e de fiscalização com agências equatorianas e peruanas.

A definição legal e jurídica da noção de "tráfico de pessoas" já levantou alguns debates não só na academia, mas também em ambientes políticos. Adriana Piscitelli (2013) chama a atenção, por exemplo, para os impasses e as confusões conceituais em relação à sua definição e às noções utilizadas nos instrumentos legais nacionais e internacionais. No Protocolo de Palermo (Protocolo Adicional à Convenção das Nações Unidas contra o Crime Organizado Transnacional), ratificado pelo Brasil em 2004, o tráfico de pessoas corresponde ao crime de coerção ou abuso de situação de vulnerabilidade em qualquer etapa do processo do deslocamento, com o fim de explorar o trabalho do migrante em qualquer setor de atividade. No entanto, no Código Penal Brasileiro, a definição se limita às intermediações para deslocamentos cujos fins são exclusivamente exercer a prostituição e não qualquer atividade (Piscitelli 2013:100). Apesar de ser definida de maneiras diferentes e apropriada muitas vezes com objetivos distintos, a noção "tráfico de pessoas" se refere ao direcionamento do migrante para uma atividade laboral específica no local de destino.

É importante assinalar um detalhe contido no "relatório prévio" da missão por ele nos ajudar a refletir sobre as disputas de enquadramentos e sobre os argumentos utilizados para negociar e implementar medidas - no caso, o pedido de exigência de visto feito ao Peru e ao Equador. Na sua folha de rosto está escrito em texto impresso, como citado anteriormente, "com vistas ao desbaratamento da rede de tráfico de pessoas". Mas à caneta havia um risco no termo "pessoas" e ao lado (escrito à mão) foi colocada a palavra "migrante", de modo a esclarecer que o tráfico ao qual o relatório se referia era o de "migrantes" e não o de "pessoas". 
A expressão "tráfico de migrantes" significa a promoção com o objetivo de obter, direta ou indiretamente, um benefício financeiro da "entrada ilegal de uma pessoa num estado parte do qual essa pessoa não seja nacional ou residente permanente" (Decreto $n^{0}$ 5.016/2004). Esta, portanto, pode ser considerada a atividade na qual se enquadra juridicamente a atuação dos chamados atravessadores ou "coiotes", sujeitos conhecedores dos trajetos e das formas de burlar o controle, que lucram com a atividade de orientar e direcionar o migrante a atravessar fronteiras nacionais. A atuação de "coiotes" remete à ideia de transporte, a atividade é feita para levar a pessoa aonde ela deseja através de caminhos alternativos, fugindo do controle policial.

Diferente de "tráfico de pessoas", que corresponde, grosso modo, à atividade de dirigir o migrante para uma exploração laboral ou para a prostituição, "tráfico de migrantes" se refere à atividade que lucra especificamente com o trajeto. O conserto à caneta feito por um agente do governo federal no "relatório prévio" é interessante por indicar que antes mesmo de se ter plena informação de qual era ao certo o enquadramento jurídico em jogo nos ingressos de pessoas vindas do Haiti no Brasil - ou seja, se era "tráfico de pessoas" ou "tráfico de migrantes" - a missão tinha como um dos objetivos combatê-la.

A expressão "correta" para se referir ao tipo de atividade ilegal em jogo nas circulações de nacionais do Haiti para o Brasil só foi estabelecida, todavia, em março de 2012, quando foram abertos os trabalhos da Comissão Parlamentar de Inquérito do Tráfico Nacional e Internacional de Pessoas do Senado Federal, na cidade de Manaus, para "discutir a situação dos haitianos e das condições que enfrentam para chegar ao Brasil" (Relatório Final da CPI do Tráfico de Pessoas 2012:6). Como alegou o assessor da senadora Vanessa Grazziontin (PCdoB/AM) numa entrevista que realizei em Brasília, “[...] o objetivo da CPI era mapear as rotas de tráfico de pessoas. Enfim, e essa específica foi só para tratar dos haitianos, porque a gente estava em dúvida se realmente era só coiote ou não, fins de investigação mesmo". Durante tal audiência em Manaus, algumas autoridades enfatizaram o não enquadramento dos trânsitos desses migrantes como tráfico de pessoas. A CPI constatou que eles não foram traficados para fins de exploração e deu o caso como encerrado. Foram alegadas na reunião, contudo, as promessas feitas pelos considerados atravessadores aos estrangeiros sobre oportunidades e boas ofertas de emprego que eles encontrariam quando chegassem ao Brasil, o que não deixa de ser uma propaganda falaciosa.

Segundo Isabel Ferreira, a construção do "tráfico de pessoas" enquanto um problema social levou à concentração e à padronização de histórias heterogêneas. Operando em dois polos - o da vítima "inconsciente" e o do 
criminoso "consciente" - tal processo faz com que não se considere também a "consciência" na iniciativa de mulheres que se inserem no mercado do sexo (Ferreira 2009:94). Um paralelo pode ser traçado com as formulações e as afirmações a respeito do envolvimento de "coiotes" nos ingressos de pessoas vindas do Haiti, em que se opera também a partir da criminalização dos traficantes e da vitimização dos estrangeiros em trânsito, sem levar em conta as histórias e as decisões dos migrantes.

O combate à atuação de coiotes e ao tráfico de pessoas se tornou uma narrativa padrão nos meios de comunicação e em discursos de autoridades do governo federal, ao longo de 2011, para justificar a negociação com países vizinhos no sentido de exigir vistos de nacionais do Haiti e controlar a circulação do ingresso pela região Norte do país. Convém pensar nesta perspectiva quando olhamos para o uso de tráfico de pessoas no "relatório prévio", posteriormente revisado à caneta como tráfico de migrantes. Se a preocupação, naquele momento, incidia na possibilidade de estar em jogo um desses dois tipos de atividade, as ações para verificá-las repousaram menos em atendimentos, escutas e apoios às supostas vítimas do que na busca de acordos na área de inteligência e policial para capturar os "coiotes" e combater as redes de tráfico.

Buscaram negociar com autoridades equatorianas e peruanas, por exemplo, ações para a realização de estágios recíprocos dos órgãos policiais e de inteligência, intercâmbio permanente de informações, o estabelecimento e o reforço de cooperação jurídica para a erradicação "do contrabando de imigrantes e criminalização dos responsáveis (coiotes)", como consta no relatório da missão. Propostas bem recebidas pelas delegações, mais uma tentativa de "solução", uma dimensão de controle da circulação que foi buscada em outras missões diplomáticas realizadas posteriormente pelo governo brasileiro para insistir no pedido de visto ao governo equatoriano.

\section{O governo das migrações e seus efeitos}

No final de 2010 e início de 2011, como foi possível observar nos documentos analisados, os relatos sobre as dificuldades de entidades de atenderem a pessoas vindas do Haiti começaram a ser registrados e encaminhados a agências em Brasília. Os trânsitos dessas pessoas passaram a ser mais frequentes. Padres e freiras perceberam que os ingressos viraram permanentes - mesmo que indivíduos partissem, novos chegavam - começaram a aparecer algumas dificuldades: era preciso providenciar alimentação e hospedagem. Inicialmente, entidades da Rede Solidária para Migrantes e 
Refugiados e paróquias estavam dando conta da acolhida, depois foi cada vez mais difícil continuá-la. Aos poucos foi mobilizada em diferentes documentos a ideia de "situação" - e seus correlatos "problema" e "questão" - apresentada tanto a partir da preocupação com as condições dos recém-chegados quanto com as possíveis dificuldades para a gestão. Penso aqui gestão num sentido amplo: dos corpos, do município, da paróquia, do Departamento da Polícia Federal, da fronteira, de uma população.

Enquanto se construía um desbordo, a expectativa de uma "solução" acompanhava as percepções e as ações de variados atores, por isso as tentativas de acionar os ministérios em Brasília. Inerente à afirmação de uma situação estava a perspectiva de mudança: a possibilidade de uma intervenção poder reverter o que se apresentava. A percepção da frequência e não mais da eventualidade, da presença e não mais da passagem, induziu a respostas positivas e negativas.

Vimos algumas ações de padres, freiras e autoridades (tanto do governo federal quanto do governo do Acre). À medida que eram empreendidas tinham como foco um coletivo de pessoas paulatinamente modulado como uma "população", um objeto a ser gerido. Se esta "população" passou a ser lida pela sua necessidade, vulnerabilidade, motivando articulações para providenciar ajuda, o ingresso de pessoas vindas do Haiti induziu também preocupações pelos riscos que, na visão de algumas agências, eles levantavam. Foram desenvolvidas, assim, ações que iam desde as intervenções sobre os corpos das pessoas vindas do Haiti, através da realização de exames, às relações diplomáticas. Ações legitimadas internacionalmente, fundamentadas tanto em práticas em vigor desde pelo menos o século XIX (vigilância sanitária e o controle de epidemias) como em convenções internacionais (no caso me refiro ao protocolo de Palermo), acordadas enquanto verdades e apropriadas com interesses diversos. No intercâmbio de tensões e acordos eram produzidas zonas de atuação.

O artigo procurou chamar a atenção para as ações de variadas instâncias do "governo dos outros" (entidades religiosas, prefeitura, governo do estado, governo federal, governo de países vizinhos, mídias) e mecanismos de controle. Ao fazermos a genealogia da construção de um "problema", vemos como essas diferentes dimensões de governo se conectam e estão mais embrenhadas do que parece.

O final de 2010 e o início de 2011 significaram um primeiro momento da construção do "caso dos haitianos". Nos anos seguintes, o assunto não saiu mais da mídia, das discussões no Conselho Nacional de Imigração (CNIg-MTE) e de reuniões interministeriais. Mês a mês, ano a ano, as notícias repetiram o seu tom alarmista de "invasão de haitianos", o gover- 
nador do Acre pedia ajuda ao governo federal e as entidades que lidam com migrantes e refugiados no Brasil se mobilizavam para solicitar uma postura mais humana em relação às pessoas em trânsito. O que chamamos aqui de primeiro momento da construção do "caso dos haitianos" está relacionado ao processo de nomear uma nova dinâmica: o "ingresso de haitianos". Mas demorou ainda certo tempo (meses e anos), eventos se sucederam (mudança de cargos em Brasília, criações de normativas, atenção na mídia internacional) para que agências do governo federal passassem a notar que era mais tático e menos custoso gerir as circulações de nacionais do Haiti da maneira que elas se apresentavam, em vez de buscar evitá-las e impedi-las.

Do embrenhado de disputas, o governo federal nos últimos quatro anos acabou reforçando uma matriz "humanitária" em relação aos ingressos de pessoas vindas do Haiti, não os deportando e viabilizando a retirada de vistos em Porto Príncipe. As atitudes de não deportar e regularizar os indivíduos de acordo com pressões e visibilidades na mídia podem ser inseridas numa lógica mundial. Dar uma resposta humanitária não deixa de ser uma das condições para o país se ver legitimado em fóruns internacionais, principalmente por conta do comando da Minustah. Esses processos criaram alguns "efeitos de Estado" (Mitchell 1999; Trouillot 2001). Um efeito desejado pelo governo federal no sentido de que o Estado brasileiro atuou de maneira humanitária, reforçando certo mito de Estado enquanto uma entidade acolhedora.

Mas o ingresso de pessoas haitianas também gerou outros efeitos, como a visibilidade das atuações das pastorais e o reforço das suas articulações em rede; despertou "medos" de doenças; reações racistas e alarmistas; rearranjos e negociações políticas. Movimentou uma variedade de agentes, e a academia, certamente, não ficou fora disso. ${ }^{21}$ Resta saber como tecer análises quando pronunciamentos políticos, notícias de jornal e artigos acadêmicos parecem se misturar. Fazer a genealogia da construção de um problema talvez seja uma alternativa para refletir sobre nossos próprios discursos e ações, observar como coisas são registradas e produzidas, uma categoria de gestão é criada, uma população vira foco de ações e atenções. Pode ajudar a pensar em quais lógicas estavam em jogo em determinado momento - a lógica do migrante, "daquele que não é daqui", daquilo que ameaça certa ordem - para não reproduzirmos, inclusive, essas mesmas lógicas.

Recebido em 26 de dezembro de 2016

Aprovado em 30 de março de 2017 
Rosa Vieira é doutoranda em Antropologia Social no Programa de Pós-Graduação em Antropologia Social, Museu Nacional, Universidade Federal do Rio de Janeiro. E-mail: < ribasrosa@yahoo.com.br >

\section{Notas}

* Este artigo é fruto de partes do segundo capítulo da minha dissertação de mestrado desenvolvida no Programa de Pós-Graduação em Sociologia e Antropologia da Universidade Federal do Rio de Janeiro (PPGSA/ UFRJ), sob orientação do Prof. Fernando Rabossi. Uma primeira versão do texto foi apresentada numa reunião do NIEM/UFRJ e agradeço aos participantes pelos comentários. Também agradeço ao Prof. Federico Neiburg e aos pareceristas da Mana pelas sugestões e leitura.

1 O questionamento de uma visão unilateral do processo migratório foi feito também, em outra chave analítica, por Palmeira e Wagner (1977) e Garcia (1990) que problematizaram a ideia da "emigração por mão única".

2 De acordo com estimativas do Conselho Nacional de Imigração (CNIg), mencionadas no portal Brasil do governo federal, em 2016 havia cerca de 80 mil nacionais do Haiti no país.

3 O artigo, portanto, aborda documentos que não estão propriamente em arquivos oficiais abertos ao público, mas que foram acessados e reunidos por conta de interações e diálogos com gestores e funcionários, e através de observações ao longo de trabalho de campo em Brasília. Para outros trabalhos etnográficos que se pautaram em documentos administrativos e burocráticos, cf. Vianna (2014); Lowenkron e Ferreira (2014).

4 A perspectiva do autor não é utilizada no trabalho de maneira abstrata, mas sim pelas questões que ela possibilita levantar. Como sugere Neiburg (2014), ela oferece instrumentos para que não se permaneça focado no poder do "Estado-nação", o que permite discutir arranjos, mapear configurações e espaços de contradições.

5 A ideia de "problema de governo" utilizada é inspirada na maneira como Michel Foucault entende a "problematisation", base para a sua proposta de uma "histoire de la pensée" (cf. Foucault 1994:597).

6 A aproximação com a ideia de problematisation de Foucault foi feita por Daniel Hirata em sua análise sobre o comércio de rua enquanto "problema" no Rio de Janeiro e São Paulo (cf. Hirata 2014). 
7 É importante assinalar que pessoas vindas do Haiti não foram reconhecidas como refugiadas pelo Comitê Nacional para Refugiados (Conare-MJ), porque nos formulários de solicitação não constavam alegações de perseguição e nem de medo de retornar ao país de proveniência, condições prescritas na Lei nº 9474/1997 para a concessão do refúgio. Mas elas foram regularizadas através de resoluções normativas - $\mathrm{RN} \mathrm{n}^{\circ}$ 27/97 e RN no 97/2012 (reformulada posteriormente pela RN no 102/2013) elaboradas pelo Conselho Nacional de Imigração (CNIg-MTE). Para uma discussão sobre esses processos de regularização, cf. Vieira (2014).

8 A Rede para Migrantes e Refugiados é dirigida pela Irmã Rosita Milesi e constitui a articulação de um conjunto de instituições da sociedade civil, algumas confessionais outras não, que lidam com migrantes e refugiados no Brasil.

9 Este e-mail foi enviado ao endereço infoap@planalto.gov.br. Tive acesso a ele através de uma pessoa do governo federal que me passou o impresso anexado a outros documentos e relatórios.

10 Deve ser salientado que o relatório não tem uma data de elaboração, apenas a data do seu encaminhamento para outras agências: janeiro de 2011.

11 Folha de São Paulo (2011). Acre é rota de entrada de haitianos no país. São Paulo, 21 de janeiro de 2011.

12 Para uma análise da dinâmica pós-terremoto em Porto Príncipe que explora os desdobramentos produzidos pelo retorno aos seus bairros de alguns dos que estavam presos, cf. Braum (2014).

13 De acordo com registros da DPF, durante o ano de 2010 foram registradas 456 solicitações de refúgio em Tabatinga e cinco em Manaus.

14 A Crítica (2011). FVS chega a Tabatinga para enfrentar cólera. Manaus, 8 de fevereiro de 2011.

15 Oiapoque no Amapá é uma das cidades que fazem parte do trajeto buscado por pessoas do Haiti para alcançar a Guiana Francesa.

16 De acordo com dados do Centro Nacional de Epidemiologia (Cenepi) da Fundação Nacional de Saúde (Funasa) do Ministério da Saúde (MS), entre 1991 e 1996, foram notificados ao Ministério da Saúde por volta de 154.415 casos de cólera no Brasil (cf. Gerolomo \& Penna 1999). No Haiti, o surto de cólera que se iniciou em 2010 atingiu 470 mil pessoas e teve cerca 6.631 mortes (ver Centers of Disease Control and Prevention. Disponível em: http://www.cdc.gov/haiticholera/haiti_cholera. htm [Acesso em 19/10/2016]). Sobre a criação de uma Cooperação Tripartite Brasil-Haiti-Cuba para fortalecer o sistema de saúde e de vigilância epidemiológica no Haiti, cf. Esteves (2016).

17 Brasil, Kátia \& Freitas, Fábio. Folha de São Paulo. Governo federal autoriza a permanência de mais 199 haitianos no Brasil. São Paulo, 16 de março de 2011.

18 Informações sobre essa reunião constam no relatório já citado "Informação ao senhor ministro de estado: fluxo migratório haitiano em direção ao Brasil". 
19 Cf._El diário. Ecuador prevé regularizar a unos 500 haitianos con “amnistía migratoria". s/a. Quito, 10 de fevereiro de 2010.

20 Chamo de "relatório prévio" da missão um documento que estava anexado ao relatório da missão a que tive acesso. Utilizo prévio, pois nele constava a agenda da missão e os objetivos das reuniões diplomáticas.

21 A menção à "academia" se refere a um conjunto bastante heterogêneo de pesquisas de áreas variadas sobre o ingresso de pessoas haitianas no Brasil (cf. Silva 2012; Faria 2013; Costa 2012; Thomaz 2013; Cotinguiba 2014; Véran 2014; Fernandes \& Castro 2014; Vieira 2014; Handerson 2015; Cogo \& Silva 2016). 


\section{Referências bibliográficas}

BRAUM, Pedro. 2014. Ratpakaka: política, desenvolvimento e violência no coração de Porto Príncipe. Tese de Doutorado em Antropologia Social, Museu Nacional, Universidade Federal do Rio de Janeiro.

BRASIL. 1997. Lei no 9474, de 22 de julho de 1997. Diário Oficial da União, Seção 1: 15822. 23/7/1997.

CHALHOUB, Sidney. 1993. "The politics of desease control: yellow fever and race in nineteenth Rio de Janeiro". Journal of Latin American Studies, 25(3):441-463.

COGO, Denise \& SILVA, Terezinha. 2016. "Entre a fuga e a invasão: alteridade e cidadania da imigração haitiana na mídia brasileira". Revista Famecos: mídia, cultura e tecnologia, 23(1).

COMERFORD, John. 2015. "Onde está a comunidade? Conversas, expectativas morais e mobilidade em configurações entre o rural e o urbano". Ruris, 8(2):7-29.

COSTA, Pe. Gelmino A. 2012. "Haitianos em Manaus: dois anos de imigração - e agora!". Travessia - Revista do Migrante, 70:91-99.

COTINGUIBA, Geraldo Castro. 2014. Imigração haitiana para o Brasil: a relação entre trabalho e processos migratórios. Dissertação de Mestrado em História e Estudos Culturais, Universidade Federal de Rondônia/ UNIR/RO.

ESTEVES, Uliana. 2016. “'Tèt asanm pou la sante': apontamentos etnográficos sobre a cooperação internacional para a saúde no Haiti". História, Ciências, Saúde. Manguinhos, 23(2):523-541.
FARIA, Andressa V. 2013. A diáspora haitiana para o Brasil: o novo fluxo migratório (2010-2012). Dissertação de Mestrado, Programa de Pós-Graduação em Geografia, Universidade Católica de Minas Gerais.

FARMER, Paul. 1992. Aids and accusation: Haiti and the geography of blame. Oakland: University of California Press.

FASSIN, Didier. 2011. "Policing borders, producing boundaries. The governmentality of immigration in dark times". Annual Review of Anthropology, 40:213-226.

FERNANDES, Duval \& CASTRO, Maria. 2014. Estudos sobre a migração haitiana ao Brasil e diálogo bilateral. Belo Horizonte: Ministério do Trabalho e Emprego/PUC Minas.

FERREIRA, Isabel. 2009. A construção social do tráfico de pessoas. Dissertação de Mestrado em Antropologia Social, Museu Nacional, Universidade Federal do Rio de Janeiro.

FOUCAULT, Michel. 2008. Segurança, território e população. Curso dado no Collège de France (1977-1978). São Paulo: Martins Fontes. . 1994. Dits et écrits. Tome IV. Paris: Gallimard.

GARCIA, Afrânio. 1990. O Sul: caminho do roçado. Estratégias de reprodução camponesa e transformação social. São Paulo: Brasília.

GEROLOMO, Moacir \& PENNA, Maria Lúcia. 1999. "Os primeiros cinco anos da sétima pandemia de cólera no Brasil". Informe Epidemiológico do SUS, 8(3):49-58. 
GLICK-SCHILLER, Nina \& FOURON, Georges. 2001. Georges woke up laughing: Long-distance nationalism and the search for home. Durham: Duke University Press.

GUEDES, Andre. 2013. O trecho, as mães e os papéis. Etnografia de movimentos e durações no norte de Goiás. Rio de Janeiro: Garamond.

HANDERSON, Joseph. 2015. Diáspora. As dinâmicas da mobilidade haitiana no Brasil, no Suriname e na Guiana Francesa. Tese de Doutorado em Antropologia Social, Museu Nacional, Universidade Federal do Rio de Janeiro.

HIRATA, Daniel. 2014. "Street commerce as a 'problem' in the cities of Rio de Janeiro and São Paulo". Vibrant, 11(1):96-117.

HULL, Matthew. 2012. Government of paper: the materiality of bureaucracy in urban Pakistan. Berkeley/ Los Angeles/ London: University of California Press.

LOWENKRON, Laura \& FERREIRA, Letícia. 2014. "Anthropological perspectives on documents: Ethnographic dialogues on the trail of police papers". Vibrant - Virtual Brazilian Anthropology, 11(2):75-111, July-December.

MITCHELL, Timothy. 1999. "Society, economy, and the State-effect". In: Steinmetz (ed.), State/culture: State-formation after the cultural turn. Ithaca, NY/London: Cornell University Press. pp. 76-97.

NEIBURG, Federico. 2010. "O Haiti antes e depois do terremoto". O Globo, Rio de Janeiro, 24 de janeiro. . 2014. "Foucault em chave etnográfica: o governo dos guèto de Porto Príncipe". Análise Social, 212(3):742-747.
PALMEIRA, Moacir \& BERNO DE ALMEIDA, Alfredo Wagner. 1977. A invenção da migração. Projeto emprego e mudança socioeconômica no Nordeste. Rio de Janeiro: Museu Nacional/UFRJ.

PISCITELLI, Adriana. 2013. Trânsitos: brasileiras nos mercados transnacionais do sexo. Rio de Janeiro: Editora UERJ.

RABOSSI, Fernando. 2004. Nas ruas de Ciudad del Este: vidas e vendas num mercado de fronteira. Tese de Doutorado em Antropologia Social, Museu Nacional, Universidade Federal do Rio de Janeiro.

REBELO, Fernanda; MAIO, Marcos Chor \& HOCHMAN, Gilberto. 2011. “O princípio do fim: o 'torna viagem', a imigração e a saúde pública no Porto do Rio de Janeiro em tempos de cólera". Revista de Estudos Históricos, 24(47):69-87.

REBELO, Fernanda. 2010. A travessia: imigração, saúde e profilaxia internacional (1890-1926). Tese de Doutorado em Saúde Pública, Fundação Oswaldo Cruz.

RICHMAN, Karen. 2008. Migration and vodou. Gainesville: University Press of Florida.

SILVA, Sidney. 2012. "'Aqui começa o Brasil'. Haitianos na tríplice fronteira e Manaus". In: . (org.), Migrações na Pan-Amazônia, fluxos, fronteiras e processos socioculturais. São Paulo: Hucitec/Editora Fapeam. p. 300-322. THE WORLD FACTBOOK, CIA. 2016. Disponível em: https://www.cia. gov/library/publications/the-world-factbook/geos/print_ha.html. Acesso em: 29/04/2017.

THOMAZ, Diana Z. 2013. "Migração haitiana para o Brasil pós-terremoto: indefinição normativa e implicações políticas". Primeiros Estudos, 4:131143. 
TROUILLOT, Michel-Rolph. 2001. "The anthropology of the state in the age of globalization. Close encounters of the deceptive kind". Current Anthropology, 42(1):125-138.

VELASCO, Juan Carlos. 2014. "La migración es cosa de metáforas: Los giros retóricos exageran el número de inmigrantes y los pintan como hostiles". El País, Madri, 28 de março.

VÉRAN, J.F. et al. 2014. "Nem Refugiados, nem Migrantes: A chegada dos haitianos à cidade de Tabatinga (Amazonas)". DADOS - Revista de Ciências Sociais, 57(4):1007-1041.

VIANNA, Adriana. 2014. "'Etnografando documentos': uma antropóloga em meio a processos judiciais". In:
S. R. Castilho; C. Teixeira \& A. C. Souza Lima (orgs.), Antropologia das práticas de poder: reflexões etnográficas entre burocratas, elites e corporações. Rio de Janeiro: Contra Capa. pp. 43-70.

VIEIRA, Rosa. 2014. Itinerâncias e governo: a mobilidade haitiana no Brasil. Dissertação de Mestrado em Sociologia e Antropologia, Universidade Federal do Rio de Janeiro. . 2016. "Circulações e detenções: dos casos eventuais a uma categoria de governo". Rev. Igarapé, 1(1):82-98.

WEBER, Max. 1974. "Burocracia". In: Ensaios de sociologia. $3^{\mathrm{a}}$. ed. Rio de Janeiro: Zahar Editores. pp. 229-282.

\section{Legislação}

BRASIL. Lei no 9474, de 22 de julho de 1997. Diário Oficial da União, Seção 1, p. $15822,23 / 7 / 1997$.

BRASIL. Decreto ${ }^{\circ}$ 5.016, de 12 de março de 2004. Diário Oficial da União, Seção 1, p. 8, 15/3/2004.

MINISTÉRIO DO TRABALHO E EMPREGO. Resolução Normativa ${ }^{\circ} 27$, de 25 de novembro de 1998. Diário Oficial da União, Seção 1, p. 6.
MINISTÉRIO DO TRABALHO E EMPREGO. Resolução Normativa $\mathrm{n}^{\circ}$ 97, de 12 de janeiro de 2012. Diário Oficial da União, Seção 1, p. 19, 13/01/2012.

MINISTÉRIO DO TRABALHO E EMPREGO. Resolução Normativa $\mathrm{n}^{\circ}$ 102, de 26 de abril de 2013. Diário Oficial da União, Seção 1, n. 81, p. 96. 


\section{Documentos}

Informe da Pastoral da Mobilidade Humana, Ir. Patrícia, 08 de janeiro de 2012.

Informe da Pastoral do Migrante de Manaus, Pe. Gelmino Costa e Irmã Rosa Maria, 7 de fevereiro de 2011a. Informe da Pastoral do Migrante de Manaus, Pe. Gelmino Costa, 16 de março de 2011.

Informe do Serviço Pastoral dos Migrantes, Arquidiocese Manaus, Ir. Rosa Maria e Pe. Gelmino Costa, 07 de fevereiro de 2011.

E-mail enviado à presidente da República, 14 de janeiro de 2011.

Ministério da Saúde. Relatório Situacional. Migrantes haitianos no Acre - risco de reintrodução da cólera no Brasil, 07 de fevereiro de 2011.

Ofício $N^{\circ}$ 043/11. GSJPED, de autoria do senador João Pedro (PT/AM).

Organização das Nações Unidas, Protocolo de Palermo [Protocol to Prevent, Suppress and Punish Trafficking in Persons, Especially Women and Children, supplementing the United Nations Convention against Transnational Organized Crime], de 15 de novembro de 2000, entrada em vigor em 25 de dezembro de 2003.

Relatório da Pastoral do Migrante de Manaus, Ir. Rosa Maria, 04 de março de 2011.
Relatório da Reunião do Gabinete de Gestão de Crise do Ministério da Saúde, 14 de fevereiro de 2011.

Relatório da situação epidemiológica das doenças diarreicas agudas (DDA) do município de Oiapoque-AP e controle de entrada de haitianos no município, s/d, 2011.

Relatório de inteligência: Migração de haitianos para o Brasil, 21 de outubro de 2010.

Relatório Final da Comissão Parlamentar de Inquérito do tráfico de pessoas. Dezembro de 2012. Disponível em: https://www12.senado.leg.br/retrospectiva2012/news/cpi-do-trafico-de-pessoas-aprova-relatorio-final-com-proposta-de-mudanca-na-lei-penal. Acesso em: 20/02/2017.

Relatório prévio: Missão ao Equador e Peru - Imigração Haitiana, fevereiro/ março de 2010.

Relatório: Equador e Peru. Assuntos consulares e migratórios. Imigrantes haitianos. Missão brasileira, março de 2011.

Relatório: Informação ao Senhor Ministro de Estado: fluxo migratório haitiano em direção ao Brasil, janeiro de 2011. 


\section{O GOVERNO DA MOBILIDADE HAITIANA NO BRASIL}

\section{Resumo}

O presente artigo traça um primeiro momento da construção de um caso de governo da mobilidade haitiana no Brasil, quando, no início de 2011, a categoria "haitianos" passa a ser inscrita acompanhada de palavras como "fluxo", "problema", "questão". Através da análise de uma variedade de documentos (ofícios, relatórios ministeriais, boletins informativos de entidades religiosas) que permitem mapear a comunicação entre atores e agências situados no Amazonas, Acre e Brasília, a proposta é discutir os esforços de classificar uma nova mobilidade e as ações tanto humanitárias quanto de controle para evitar o aumento dos ingressos. O artigo sugere que estas narrativas e ações delinearam um objeto de governo, um problema a ser gerido e zonas de intervenção.

Palavras-chave: Haitianos, Circulação, Ajuda humanitária, Controle, Brasil.

\section{THE GOVERNM ENT OF HAITIAN MOBILITY IN BRAZIL}

\section{Abstract}

This article analyses a first moment in the construction of a government case about Haitian mobility in Brazil, when, in early 2011, the category "Haitians" becomes mobilized alongside words like "flow", "problem", "issue". Through the observation of a variety of documents (official letters, ministerial reports, informative reports of religious organizations), which maps the communication of actors and agencies localized in the Brazilian states of Amazonas and Acre, and in the Federal District, the article discusses efforts to qualify and frame a new mobility, as well as humanitarian activity and the attempts control migration. The article suggests that these discourses and actions delineate a governmental object, a problem to be managed, and zones of intervention.

Key words: Haitians, Circulation, Humanitarian aid, Control, Brazil. 


\section{EL GOBIERNO DE LA MOVILIDAD HAITIANA EN BRASIL}

\section{Resumen}

El presente artículo describe un primer momento de la construcción de un caso de gobierno sobre la movilidad haitiana en Brasil, cuando, a inicios de 2011, la categoría "haitianos" pasa a ser acompañada de palabras como "flujo", "problema", "cuestión".
A través del análisis de documentos que mapean la comunicación entre actores y agencias situadas en los estados brasileños de Amazonas y Acre, y en el Distrito Federal, la propuesta es discutir los esfuerzos de clasificar una nueva movilidad y las acciones tanto humanitarias como de control para evitar el aumento de los ingresos. El artículo sugiere que estas narrativas y acciones delinean un objeto de gobierno, un problema para ser gestionado y zonas de intervención.

Palabras clave: Haitianos, Circulación, Ayuda humanitaria, Control, Brasil. 